\title{
Working with Patients and Members of the Public: Informing Health Economics in Child Health Research
}

\author{
Rebecca Kandiyali, ${ }^{1,2} \cdot$ Annie Hawton $^{3} \cdot$ Christie Cabral $^{4} \cdot$ Julie Mytton $^{2,5} \cdot$ Valerie Shilling $^{6} \cdot$ Christopher Morris $^{7}$. \\ Jenny Ingram²
}

Published online: 15 October 2018

(c) The Author(s) 2018

\begin{abstract}
This paper considers patient and public involvement (PPI) in health economics research and how this might be facilitated. PPI refers to research carried out 'with' or 'by' members of the public and is now an important aspect of health research policies internationally. Patients and members of the public can be involved in all stages of the research cycle, from establishing whether the topic is important to influencing details of study design, wording of patient-facing documentation and interpretation and dissemination of findings. PPI has become commonplace in health services research. In the context of clinical trials, it has become imperative, with, for example, patients and members of the public informing the selection of outcome measures and recruitment methods, and qualitative research is frequently steered by PPI input regarding the content of interview topic guides and the interpretation of study findings. It is less common for PPI to be explicitly reported in the economic components of health services research. However, we argue that involvement is no less important in this area. The fundamental rationale for involving people in research is that it promotes democratic principles, research quality and relevance to service users. These arguments equally apply to health economics as to other health research disciplines. Our overarching aim in this paper is to show how health economic research might be informed by PPI. We report our experiences of PPI via case studies in child health, reflect on our learnings, and make suggestions for future research practice.
\end{abstract}

\section{Plain Language Summary}

This paper considers how to involve patients and members of the public in health economics research.

Health economists often carry out research into the value for money (sometimes called 'cost effectiveness') of new ways of treating people. This can help in decisions about which treatments are publically funded. In an economic evaluation, the economist identifies and values the key things used to treat someone who is unwell. They also have to measure how unwell that person is and whether their health changes with treatment. They do this by asking them questions about how they rate specific aspects of their health. Economists compare costs and health outcomes of different treatments. Patient and public involvement in health research is really important because the public fund health systems (through taxation in the UK) and benefit from healthcare. This paper shares our ideas on and experiences involving the public in health economic research studies. All our examples come from the involvement of children and/or parents. We think our approaches would also apply to adults.

Rebecca Kandiyali

rebecca.kandiyali@bristol.ac.uk

1 Health Economics at Bristol, Population Health Sciences, Bristol Medical School, University of Bristol, Bristol, UK

2 Centre for Academic Child Health, Bristol Medical School, University of Bristol, Bristol, UK

3 Health Economics Group, University of Exeter Medical School, University of Exeter, Exeter, UK
4 Centre for Academic Primary Care, Bristol Medical School, University of Bristol, Bristol, UK

5 University of the West of England, Bristol, UK

6 University of Sussex, Sussex Health Outcomes Research and Education in Cancer (SHORE-C), Brighton, Brighton and Hove, UK

7 PenCRU, University of Exeter Medical School, University of Exeter, Exeter, UK 


\section{Background}

Patient and public involvement (PPI) is where "people are not the subjects of research but are working with researchers to plan, manage and carry out research" [1]. PPI is becoming an important aspect of health research internationally [2-6], although the nomenclature differs across countries, with terms such as 'engagement' and 'consumer', 'community' and 'citizen' involvement sometimes used to mean the same thing.

In England, INVOLVE is the UK national advisory group responsible for promoting PPI in research [7]. A key resource for intending researchers, it provides guidance as to what does and does not constitute PPI. Examples include the option for members of the public to be co-applicants on research projects, be involved in identifying research topic priorities, be members of project advisory and steering groups, support the development of patient information leaflets and research materials, undertake interviews with research participants and analyse results and help disseminate findings. Broad guidance is available on what PPI is and is not, but discussion of the application of PPI within the framework of economic evaluation is limited [8].

In healthcare, resources are finite. Interest in health economics, and specifically the framework of economic evaluation-a mechanism for prioritising healthcare decision making and spending - has increased in the past 50 years. In the field of child health, several recent key government, parliamentary and professional reports have highlighted the need for evidence-based policy, with recommendations focusing on the economic case for investment in early years child health and public health [9-12].

We are aware of many health economists who seek to involve patients and members of the public in their studies, but our experience is that involvement in this area can be challenging, partly because of perceptions of health economics as a technically dominated discipline removed from the more immediate concerns of the patient. As a multidisciplinary group of researchers and health economists, we wished to reflect on our experiences and initiate discussion regarding how to facilitate public involvement in future health economics research. The aims of this paper are (1) to share examples of how PPI has supported and influenced the economics component of health research studies evaluating interventions with parents to support child health and (2) to promote PPI in future health economics research.

\section{Examples of Patient and Public Involvement (PPI) in Health Economics}

In this report, we document three examples from our own experiences of PPI in health economics, discuss the practical approaches, reflect on what we learned and, finally, make suggestions for researchers seeking PPI in economic studies. We focus on three case studies of projects that were funded by the National Institute of Health Research (NIHR): a feasibility study of a parenting programme to prevent home injuries in pre-school children [13], a feasibility randomized controlled trial (RCT) of a complex intervention to improve the management of children presenting to primary care with acute cough [14] and Parent-to-Parent support, a study of the benefits and costs of a one-to-one peer-support service for parents of disabled children [15-17] (Table 1). As with any study where public involvement is planned, researchers undertaking health economic research need to consider who to involve and why, when and how to involve them (see Box 1) [18]. We describe this process in the context of our own experiences of PPI and working with young people and their families, in each case reporting in accordance with the Guidance for Reporting Involvement of Patients and the Public 2-short form (GRIPP2 SF) checklist [19] (Table 2).

\subsection{Box 1: Basic Questions for Planning Patient and Public Involvement}

\section{Why involve?}

The advantages of involving young people and their families in child health research are clear: it ensures relevance and that research focuses on the needs of young people. There is also a democratic imperative: people who are affected by research have a right to have a say in what and how publically funded research is undertaken [18]. The 'why' needs to consider the rationale for involvement in the context of the particular study question. Very often, health economic research will be nested in clinical studies (i.e. economic evaluations are often nested in health technology assessments), which may have some planned PPI work already. Researchers will need to consider whether the planned PPI work can also meet the needs of the economic study or whether additional involvement is needed for the health economic elements of the project.

\section{Who to involve?}

Where research studies are principally in populations involving children, the 'who' identifies whether it is the child's and/or the primary carer's involvement that should be sought and whether those included should have 'lived experience' of the condition, either directly as a patient or indirectly as a carer. Economic studies that value health 
Table 1 Details of child and family case studies where patient and public involvement informed the health economic study

\begin{tabular}{|c|c|c|c|}
\hline & FAST & $\mathrm{CHICO}$ & Parent-to-Parent \\
\hline Context & $\begin{array}{l}\text { Enhancing parenting to prevent } \\
\text { home injuries in pre-school } \\
\text { children }\end{array}$ & $\begin{array}{l}\text { Reducing antibiotic prescribing in } \\
\text { children's cough }\end{array}$ & $\begin{array}{l}\text { One-to-one peer support for parents } \\
\text { of disabled children }\end{array}$ \\
\hline Study design & Single-arm feasibility trial & $\begin{array}{l}\text { Single-centre feasibility cluster } \\
\text { RCT }\end{array}$ & Programme evaluation \\
\hline $\begin{array}{l}\text { Population (target for interven- } \\
\text { tion) }\end{array}$ & Parents (child health) & Parents (child health) & Parents (family health) \\
\hline Intervention & $\begin{array}{l}\text { Parenting programme incorporat- } \\
\text { ing first aid skills and injury- } \\
\text { prevention education }\end{array}$ & $\begin{array}{l}\text { Web-based behavioural method } \\
\text { used within consultation }\end{array}$ & $\begin{array}{l}\text { One-to-one peer-befriending } \\
\text { service }\end{array}$ \\
\hline Comparator & - & Usual care & $\begin{array}{l}\text { Single and multiple coordinator } \\
\text { service models }\end{array}$ \\
\hline $\begin{array}{l}\text { Primary (or intended primary) } \\
\text { study outcome measure }\end{array}$ & Injuries at baseline and follow-up & Level of antibiotic prescribing & \\
\hline Economic outcomes & Healthcare resource use & $\begin{array}{l}\text { Resources required to care for } \\
\text { children with respiratory tract } \\
\text { infection from the viewpoint of } \\
\text { the NHS and families, including } \\
\text { lost productivity and child- } \\
\text { reported HRQoL }\end{array}$ & $\begin{array}{l}\text { Costing study of resources required } \\
\text { to provide service }\end{array}$ \\
\hline Perspective & $\begin{array}{l}\text { NHS and personal and social } \\
\text { services }\end{array}$ & NHS and personal resource use & $\begin{array}{l}\text { Third sector and personal resource } \\
\text { use }\end{array}$ \\
\hline
\end{tabular}

CHICO CHIldren's COugh study, FAST First-aid Advice and Safety Training parenting programme, HRQoL health-related quality of life, NHS national health service, $R C T$ randomized controlled trial

and impact on decision making involve questions relat-
ing to the appropriateness of child involvement. These
include the ethical obligations of the research team (i.e.
the duty to avoid harm if involvement in research could
be upsetting and perhaps also a responsibility to the child
to ensure their voice is heard) [20]. Other more practical
issues include how to enable children of different ages and
stages of development to understand the choices available
and how to express an opinion. This may be particularly
challenging in the context of health economics research,
which can be jargon heavy. However, with careful plan-
ning, early discussion, jargon busting and ongoing sup-
port, young people can be involved in the research process.

\section{How to involve?}

The 'how' might relate to the practicalities of involving members in a session, or over a series of sessions, in terms of scheduling, ways of working together, reimbursements, special requirements of involved groups, etc. In studies where PPI is planned to inform the economic evaluation, some explanation of definitions and principles may be required to make the economic component accessible.

\section{When to involve?}

There may be potential for involvement at different stages of the research cycle. Identifying when to involve people might naturally follow from answers to the question why to involve. For instance, when preparing a grant application, awarding bodies commonly ask about public involvement. There may be options to involve people in the preparation of funding applications, in the design of the research, during the study or once it has concluded to spearhead efforts to implement and/or disseminate study findings.

\subsection{Case Study 1: The FAST (First-aid Advice and Safety Training [FAST] Parenting Programme) Study}

Why? The primary outcome for the study was parentreported child injuries sustained at home. As parents may have been concerned that frequent reporting of injuries would lead to judgements about their parenting ability, PPI was crucial to understand how to engage parents in disclosing injuries and recording which healthcare services had been used. The economic component of the feasibility study determined the resource utilisation and costing data that would need to be collected in a full trial.

Who? A parent advisory group (PAG) was formed of young parents with one or more children under the age of 5 years. Facilitated through, and based at, a children's centre, the PAG involved parents who may not otherwise have engaged in research. 
How? To capture both the primary outcome (parentreported injuries occurring at baseline and during followup) and measures of benefit and resource use, PAG members directly influenced the development of a proposed injury diary and its transformation into a calendar that could be attached to a fridge door or a wall. The calendar design (appearance, content, utility) evolved incrementally over the sessions to reflect parent needs and feedback from PAG members. The final design enabled parent participants in the study to code multiple child injuries, noting when and where they occurred and what the carer did in response, including healthcare service use in a concise format that was usable over several months of follow-up.

Outcome of PPI: The involvement of the PAG resulted in a data-collection tool that was acceptable to parents and well completed (151 injuries reported from 22 households), indicating that parental self-recording can be used to capture the health and family resource use required for economic evaluation. The PPI involvement illustrated the burden of injuries to families and changed the economic perspective of the proposed future trial from a health perspective to a societal one to capture the broader non-national health service (NHS) costs and benefits associated with injury prevention. The potential to use the calendar in future evaluations of injury-prevention initiatives was recognised.

Critical reflection: In this study, parents voiced concerns that ultimately led to the removal of a resource use question item. However, it may not always be appropriate to entirely remove an item (or otherwise depart from a study plan) based on what patients and members of the public report they do not like. It is plausible that there may be more objection if the rationale for the economic study is poorly described and/or if the PAG does not understand the justification for the data collection. Researchers therefore need to allow time for explanation and problem solving.

\subsection{Case Study 2: The CHICO (CHIldren's COugh) Study}

Why? The rationale for PPI input was to identify what resources are required to care for children with cough and to establish the best mode of delivery of both a resource use questionnaire and a health utility measure for this population.

Who? A PAG was formed after a researcher approach to an existing parent and toddler group held in a community venue.

How? The PAG met twice yearly throughout the study. Sessions were carried out by two members of the study team who liaised with the study health economist. Meetings incorporated a PAG role-play session, with observing PAG members encouraged to comment aloud as a list of proposed questions composed by the trial health economist were asked of one of the mothers. Parents' responses revealed that certain questions on household income were intrusive and that technical labels for different types of healthcare were unfamiliar. Further consultation with parents shaped the format, content and mode of delivery of parent/carer and child materials.

Outcome of PPI: The involvement of the PAG suggested that an online resource use form would work better with parents and that an appealing booklet version of the health utility measure (the CHU-9D [Child Health Utility-9 Dimensions]) [21-23] would be easier for 7- to 11-year-olds. Parents were uncomfortable reporting details of earnings, and these sensitivities led to questions about personal income being omitted from a final version of the resource use survey (information on personal finances is not strictly necessary to capture the opportunity cost of time off work, as an imputed wage rate is commonly used). Plain English alternatives were found for technical labels. The PAG provided feedback regarding font, graphics and images that was taken to a graphic designer to make completing the survey more engaging.

Critical reflection: Researchers identified mothers easily by asking an established mother and toddler group who was willing to be involved. Such a selection method may be more suited to common illnesses and more minor ailments. However, there may be an issue with the representativeness of samples based in single community settings.

\subsection{Case Study 3: The Parent-to-Parent Support Study}

Why? The idea to carry out research about peer support for parents of disabled children grew from a topic raised by a parent. The aim of the economic component of the study was to investigate what time, resources and money is needed to provide a one-to-one peer-befriending service for parents of disabled children. The broader aim of the evaluation as a whole was to conduct the research in collaboration with Face 2 Face, a service provided by the charity Scope to connect parents with disabled children to emotional and practical support.

Who? A study stakeholder group was formed by the Face 2 Face coordinator inviting all parents with disabled children who were active befrienders in Exeter and mid and east Devon. This helped ensure data collection was relevant and likely to be feasible.

How? Work sampling is a measurement technique that allows the proportion of time spent by people on particular activities to be estimated and can "provide important insights into the cost analysis of complex interventions" [24]. Work sampling was used in the study to (1) estimate, in a systematic manner, the amount of time that befrienders spent in befriending activities and; (2) give a detailed 
Table 2 GRIPP2 short form case studies

\begin{tabular}{|c|c|}
\hline Section and topic & Extra detail \\
\hline \multicolumn{2}{|l|}{ Case study 1} \\
\hline 1. Aim & $\begin{array}{l}\text { To develop a tool for parents to report unintentional home injuries to their preschool children, including date } \\
\text { and location of the injury event, which child in the family was injured, the type of injury they sustained and } \\
\text { all of the healthcare service support they sought as a consequence of the injury }\end{array}$ \\
\hline 2. Methods & $\begin{array}{l}\text { To engage parents in all stages of the development and testing of the intervention, we established a PAG at } \\
\text { a local children's centre. Parents who routinely attended the children's centre were invited to participate in } \\
\text { the advisory group. They were approached by the staff at the children's centre and purposively sampled to } \\
\text { include a range of socioeconomic backgrounds, education levels, experience of parent groups, number of } \\
\text { children and involvement in activities at the children's centre. The PAG met in a room at the children's cen- } \\
\text { tre on days when the parents would routinely attend, and crèche facilities were provided. The PAG meetings } \\
\text { were led by one of the research team, facilitated by a member of the children's centre staff }\end{array}$ \\
\hline 3. Study results & $\begin{array}{l}\text { There were seven core members (all mothers) who attended most meetings, and two further mothers who } \\
\text { attended once. The PAG met six times during the study. In addition to the co-development of the primary } \\
\text { outcome measure-an injury calendar that recorded healthcare service use by parents of injured children- } \\
\text { the PAG members provided advice on the development of the intervention and how to identify eligible } \\
\text { families and recruit them to the proposed trial. A draft calendar, prepared by a graphic designer, was } \\
\text { presented to the PAG, and further feedback resulted in amendments to the format and content before it was } \\
\text { used in the feasibility study }\end{array}$ \\
\hline 4. Discussion and conclusions & $\begin{array}{l}\text { The PAG was central to the development of the injury outcome and service use measure. PAG members } \\
\text { informed the appearance, content and utility of the design. Although the number of data items requested for } \\
\text { each injury event was small, there was a risk of poor completion if either the format was too complicated or } \\
\text { the instructions were not understandable. In addition, we were concerned that participants in the study may be } \\
\text { anxious about reporting injuries in their child for fear of being judged as a bad parent. } 22 \text { families in the fea- } \\
\text { sibility study reported } 151 \text { injuries over the } 6 \text { months of follow-up, suggesting that the outcome measure was } \\
\text { acceptable and useable by the participants, which was attributed to the co-development of the tool with parents }\end{array}$ \\
\hline $\begin{array}{l}\text { 5. Reflections and critical } \\
\text { perspective }\end{array}$ & $\begin{array}{l}\text { In this study, parents voiced concerns that ultimately led to the removal of a resource use question item. } \\
\text { However, it may not always be appropriate to entirely remove an item (or otherwise depart from a study } \\
\text { plan) based on what patients and members of the public report they do not like. It is plausible that there may } \\
\text { be more objection if the rationale for the economic study is poorly described and/or if the PAG does not } \\
\text { understand the justification for the data collection. Researchers therefore need to allow time for explanation } \\
\text { and problem solving }\end{array}$ \\
\hline
\end{tabular}

Case study 2

1. Aim

2. Methods

To identify what resources are required to care for children with cough and to establish the best mode of delivery of both a resource use questionnaire and a health utility measure for this population

A PAG was formed after a researcher approached an existing parent and toddler group held in a community venue. The PAG met twice yearly throughout the study. Sessions were carried out by two members of the study team who liaised with the study health economist. Meetings incorporated a PAG role-play session, with observing PAG members encouraged to comment aloud as a list of proposed questions composed by the trial health economist were asked of one of the mothers. Parents' responses revealed that certain questions on household income were intrusive and that technical labels for different types of healthcare were unfamiliar. Further consultation with parents shaped the format, content and mode of delivery of parent/ carer and child materials

3. Study results

The involvement of the PAG suggested that an online resource use form would work better with parents, and an appealing booklet version of the health utility measure (the CHU-9D) [21-23] would be easier for 7- to 11-year-olds. Parents were uncomfortable reporting details of earnings, and these sensitivities led to questions about personal income being omitted from a final version of the resource use survey (information on personal finances is not strictly necessary to capture the opportunity cost of time off work as an imputed wage rate is commonly used). Plain English alternatives were found for technical labels. The PAG provided feedback regarding font, graphics and images, which was taken to a graphic designer to make the survey more engaging

4. Discussion and conclusions

5. Reflections and critical perspective

Case study 3

1. Aim
Role play contributed to the refinement of the resource use questionnaire

Our work with the mother and toddler group indicates that approaching established groups and asking for volunteers works. However, a single PPI group drawing on a small group of mothers who all lived close together may have implications in terms of representativeness

To investigate what is needed to provide a one-to-one peer-befriending service for parents of disabled children in terms of time, resources and money. The broader aim of the evaluation as a whole reflects that the research was conducted in collaboration with Face 2 Face, a service provided by the charity Scope to connect parents with disabled children to emotional and practical support 
Table 2 (continued)

\begin{tabular}{|c|c|}
\hline Section and topic & Extra detail \\
\hline 2. Methods & $\begin{array}{l}\text { A study stakeholder group was formed by the Face } 2 \text { Face coordinator inviting all parents with disabled } \\
\text { children who were active befrienders in Exeter and mid and east Devon. This ensured data collection } \\
\text { was relevant and likely to be achievable. Two involvement meetings were held with befrienders, the lead } \\
\text { researcher and the health economist to identify the main befriending activities (e.g. visits to parents, making } \\
\text { phone calls on behalf of parents, paperwork, travelling). All befrienders involved in providing the parent-to- } \\
\text { parent service were invited to these meetings. Based on the outcomes of these meetings, a work-sampling } \\
\text { form was created for completion by the befrienders in the study regarding the amount of time they spent on } \\
\text { each of these main activities }\end{array}$ \\
\hline 3. Study results & $\begin{array}{l}\text { The involvement of the befrienders with disabled children played a significant role in influencing which data } \\
\text { were included in the costing analysis, steered how the data were collected and helped provide an economic } \\
\text { explanatory framework. Involving people in deciding the categories for work sampling led to the identifica- } \\
\text { tion of the main activities and the amount of time spent in these activities from the perspective of parent } \\
\text { befrienders themselves }\end{array}$ \\
\hline 4. Discussion and conclusions & $\begin{array}{l}\text { The data collected showed the high proportion of time spent in mutual support activities between befrienders } \\
\text { and supervision activities. PPI indicated this was clearly a resource requirement in providing the service. } \\
\text { This time was therefore accounted for in the intervention costing. This was unlikely to have been identified } \\
\text { if the method of costing had been led more by researcher-based assumptions. This unanticipated perspective } \\
\text { afforded by PPI facilitated understanding and appreciation of the resources needed to provide the service } \\
\text { and why they were needed }\end{array}$ \\
\hline $\begin{array}{l}\text { 5. Reflections and critical } \\
\text { perspective }\end{array}$ & $\begin{array}{l}\text { The befrienders were surprised to be asked to be involved in the costing aspect of the research, stating that it } \\
\text { was something they were not used to being involved with. In the first group meeting, jargon was initially a } \\
\text { barrier, and the project lead needed to spend time 'translating' the health economics terminology. However, } \\
\text { by the second meeting, these issues were ironed out and the health economist had a clearer way of providing } \\
\text { explanations. What was notable was the enthusiasm of the befrienders to help steer this part of the project }\end{array}$ \\
\hline
\end{tabular}

CHU-9D Child Health Utility-9 Dimensions, $P A G$ parent advisory group, $P P I$ patient and public involvement

1: Aim (report the aim of PPI in the study). 2: Methods (provide a clear description of the methods used for PPI in the study). 3: Study results (outcomes-report the results of PPI in the study, including both positive and negative outcomes). 4: Discussion and conclusions (outcomescomment on the extent to which PPI influenced the study overall. Describe positive and negative effects). 5: Reflections and critical perspective (comment critically on the study, reflecting on the things that went well and those that did not, so others can learn from this experience)

picture of how befrienders spent their time and how they divided their time between different activities in providing the service. Prior to the work sampling, two involvement meetings were held with befrienders, the lead researcher and the health economist to identify the main befriending activities (e.g. visits to parents, making phone calls on behalf of parents, paperwork, travelling). All befrienders involved in providing the parent-to-parent service were invited to these meetings. Based on the outcomes of these meetings, a work sampling form was created for completion by the befrienders in the study regarding the amount of time they spent on each of these main activities.

Outcome of PPI: The involvement of the befrienders with disabled children during the course of the study played a significant role in influencing which data were included in the costing analysis, steered how the data were collected and helped provide an economic explanatory framework. Involving people in deciding the categories for work sampling led to the identification of the main activities and the amount of time spent in these activities from the perspective of parent befrienders themselves. The data collected showed the high proportion of time that befrienders spent supporting each other ('mutual support') and being supervised by the befriender co-ordinator. This was clearly a resource requirement in providing the service, which was accounted for in the intervention costing, and which was unlikely to have been identified if the method of costing had been more led by researcher-based assumptions. This unanticipated perspective afforded by PPI facilitated understanding and appreciation of the resources needed to provide the service and why they were needed.

Critical reflection: The befrienders were surprised to be asked to be involved in the costing aspect of the research, stating it was something they were not used to being involved with. In the first group meeting, jargon was initially a barrier, and the project lead ended up spending time 'translating' the health economics terminology. However, by the second meeting, these issues were ironed out and the health economist had a clearer way of providing explanations. What was notable was the enthusiasm of the befrienders to help steer this part of the project.

\section{Benefits of PPI Input}

We have used a case study approach to illustrate the potential ways PPI can inform the health economic components of health research studies (Table 1). In all three studies, PPI 
chiefly appeared to influence how data were collected, enabling the health economist to reflect on the feedback offered and to refine or further develop tools for capturing cost and outcome data. In addition, and perhaps more importantly, the PPI influenced which data to collect. This suggests that involvement can shape more fundamental aspects of study design. For instance, the health economists in the FAST and Parent-to-Parent studies were made aware of key areas of resource use that might otherwise have been overlooked and, in CHICO, the parent discomfort was reduced by removing sensitive questions on family finances. In the FAST study, we concluded that any future evaluation in child injury should adopt a broader societal perspective. In the Parent-toParent support study, without PPI we would not have identified the huge importance of mutual support in providing the befriending service nor the significant proportion of time that the befrienders spent supporting each other. All the case studies had implications for the identification of relevant costs and/or consequences. While our examples demonstrate PPI approaches used in research projects supporting child health, we anticipate that the outcomes may be generalizable to other populations (see Box 2).

\subsection{Box 2: Benefits of patient and public involvement in health economics research}

We believe the benefits of PPI in health economic research studies include (but are not limited to) the following.

- Ensuring inputs/outcomes and methods for measurement are acceptable, relevant and appropriate. Our involvement work focussed on self-report measures used with parents and/or children and related to issues associated with content (e.g. response burden, sensitive questions), format (e.g. diary or calendar formats, work sampling) and presentation (e.g. incorporation of 'fun' elements, including the use of graphic design/ art to promote completion rates).

- Enabling the research team to identify factors they did not know were important and avoiding researcherbased assumptions, which may be erroneous. We, as researchers, learnt more about the population of interest and context of the research through our PPI work. In our experience, this helped provide a clear description of the interventions (and alternatives), which is a key component in any costing analysis.

- Helping provide an economic explanatory framework, e.g. what resources are used and why. In other words, involvement is likely to facilitate a more realistic and accurate evaluation of the resources that are needed to provide an intervention.

\section{Discussion}

Our case study approach demonstrates that PPI can lead to more realistic and relevant data collection in health economic research, which would appear to increase the likelihood that the study recommendations are valid. Notwithstanding these benefits, aspects of the health economics discipline require consideration to facilitate PPI.

Researchers need to explain health economic research in lay language to enable PPI members to effectively participate. This requires commitment by both researchers and patients (including members of the public, parents and caregivers) to a dialogue, a belief that involving people in the research will improve it, and a belief that it is possible to facilitate the process to enable people to improve the research. Such considerations about language apply to PPI with advisory groups of all ages but may be especially true when working with children. Related to the issue of jargon is the selection of age-appropriate approaches and tasks where children are to be involved.

In summarising our results, we note that this report uses a selective case-study approach, which is a limitation. Our PPI work almost entirely focussed on self-report measures, which is unlikely to reflect the extent and scope of possible applications within health economics. Our case studies were drawn from child health and were all related to economic evaluations. Future research is needed to consider the appropriacy of these findings beyond economic evaluation, across the broader discipline of health economics, and any similarities or differences with adult health research. However, explicit discussion of PPI and health economics is very much in its infancy, and we hope our suggestions can be added to and challenged. Strengths of this study are the specific application to economic evaluation, the illustration of an application of the GRIPP2 SF within health economics research and, hopefully, the cultivation of more discussion of PPI in health economics research in the future. Insofar as jargon is a problem, we are increasingly aware of inroads between PPI and applied health researchers in related complex areas allied to health [25-28]. It is possible that the need for, and value and potential influence of, PPI requires further consideration and input from a wider group of health economists. It may be useful to survey health economists to get their views on PPI and gauge their current PPI experience and perceptions regarding possible applications.

\subsection{Suggestions}

In each of the case studies, the health economists learnt through involvement. We have structured our suggestions for practice into four general areas. 


\subsubsection{Clear Aim}

The general and specific aims of PPI should be clear because patients and members of the public need to understand why their involvement is being sought. PPI is typically aimed at improving the health and social care experiences of patients and their families [29], but the aims of PPI within economic research may be more pragmatic but still ultimately guided by this central tenet.

\subsubsection{Two-way Education Process}

PPI requires a two-way education process between patients ${ }^{1}$ and health economists. This involves demystifying what health economists do and providing explanations of health economic issues and methods using plain accessible language. It also includes considering involving patients and members of the public as partners in the research rather than in a consultative capacity. Good PPI avoids tokenism by planning PPI activities thoughtfully, with the aim in mind, and with an awareness that PPI is both dynamic and ongoing [30]. In this way, PPI may become a continuous process where health economists gain insights to be taken to the next study and patient members take their developing expertise to their next involvement activity.

\subsubsection{Impact}

Effective PPI aims to achieve meaningful health/social care improvement. This demands that the impact of PPI is captured qualitatively, quantitatively and economically [19]. The Institute of Medicine [31] proposed that impact might be measured across a 'breadth of areas', and we concur that impact might be measurable in terms of implementation, quality, patient experience, as well as health and wellbeing outcomes. While a recent literature review suggested that economic evaluation of PPI activities in health research studies generally is limited [32], it proposed a straightforward framework for capturing the cost of PPI activities that could be adopted [33]. Economic evidence of benefit of PPI is harder to define but may be demonstrable in terms of health and wellbeing outcomes [31].

\subsubsection{No Need to Reinvent the Wheel}

While it is important to think about who to involve and why, when and how to involve them [18], the use of additional frameworks for setting out PPI activities [31, 34] may be helpful. Health economists could routinely use the GRIPP2

\footnotetext{
$\overline{1}$ We intend this to include not just patients but also parents, caregivers and members of the public.
}

SF checklist [19] to help steer PPI in the studies they work on. We have used the GRIPP2 SF in relation to this paper (Table 2).

\section{Conclusions}

We have illustrated how patients and members of the public can be involved in health economics research, including the benefits we have encountered, culminating in suggestions for future practice. In accordance with good practice, we include the GRIPP-2 SF reporting checklist for each case study [19]. Further research is needed to establish the effect of PPI in terms of study findings (and impact) in the field of health economics. Impact might consider not only the potential influence on study cost and effects but also the cost of PPI in terms of research resource and the value of the approach. Input from a broad range of health economists on the use of PPI methods should now be sought.

Author contributions RK had overall responsibility for the conception of the study, drafting and revising the paper. All other authors contributed to the writing process from drafting through to final approval. The authors thank the peer reviewers who provided some very helpful comments.

\section{Compliance with Ethical Standards}

Funding No direct funding was received to write this paper; however, the FAST and CHICO studies received funding from the NIHR, and the Parent-to-Parent study received funding from the NIHR Collaboration for Leadership in Applied Health Research and Care of the South West Peninsula (PenCLAHRC) and the charity Cerebra. The views expressed in this publication are those of the authors and do not necessarily represent the views of the NHS, the NIHR, the Department of Health or the charity Cerebra.

Conflicts of Interest RK, AH, CC, JM, VS, CM and JI have no conflicts of interest.

Open Access This article is distributed under the terms of the Creative Commons Attribution-NonCommercial 4.0 International License (http://creativecommons.org/licenses/by-nc/4.0/), which permits any noncommercial use, distribution, and reproduction in any medium, provided you give appropriate credit to the original author(s) and the source, provide a link to the Creative Commons license, and indicate if changes were made.

\section{References}

1. Health and Care Research Wales. Involving the public in your research. Web page https://www.healthandcareresearch.gov.wales /involving-the-public-in-your-research/. [access date 16.02.2017]. 2017.

2. National Health and Medical Research Council. Australian Government. https://www.nhmrc.gov.au/research/consumer-andcommunity-involvement. Access date 21/03/2017. 
3. Canadian Institutes of Health Research. Framework for Citizen Engagement. http://www.cihr-irsc.gc.ca/e/41270.html. Access date $21 / 03 / 2017$.

4. National Institute for Health Research. http://www.nihr.ac.uk/patie nts-and-public/. Access date 21/03/2017.

5. New Zealand Health Research Strategy: public discussion document. https://www.health.govt.nz/publication/new-zealand-healt h-research-strategy-public-discussion-document. Access date 21/03/2017.

6. National Institutes of Health. Public Involvement at National Institute of Mental Health. https://www.nimh.nih.gov/outreach/publi c-involvement/index.shtml. Access date 21/03/2017.

7. INVOLVE. http://www.invo.org.uk/about-involve/. 2018.

8. Goodwin E, Boddy K, Tatnell L, et al. Involving Members of the Public in Health Economics Research: Insights from Selecting Health States for Valuation to Estimate Quality-Adjusted LifeYear (QALY) Weights. Appl Health Econ Health Policy. 2017.

9. Department of Health. Chief Medical Officer's annual report 2012: Our Children Deserve Better: Prevention Pays. In: Strelitz J, ed., The economic case for a shift to prevention, 2012.

10. RCPCH. State of Child Health. 2017 Recommendations for England. Available from: http://www.rcpch.ac.uk/system/files/prote cted/page/SOCH-recommendations-England.pdf. Date access: 03/03/2017. 2017.

11. The Marmot Review. Fair Society, Healthy Lives, The Marmot Review. Available at: www.ucl.ac.uk/marmotreview. Access date 03/03/2017., 2010.

12. World Health Organisation. The Partnership for Maternal, Newborn \& Child Health. PMNCH Knowledge Summary \#24 The economic benefits of investing in women's and children's health. http://www.who.int/pmnch/knowledge/publications/summaries/ knowledge_summaries_24_economic_case/en/. Access date 21/03/2017., 2013.

13. Mytton J, Ingram J, Manns $S$, et al. The feasibility of using a parenting programme for the prevention of unintentional home injuries in the under-fives: a cluster randomised controlled trial. Health Technol Assess. 2014; 18(3).

14. Turnbull SL, Redmond NM, Lucas P, et al. The CHICO (Children's Cough) Trial protocol: a feasibility randomised controlled trial investigating the clinical and cost-effectiveness of a complex intervention to improve the management of children presenting to primary care with acute respiratory tract infection. BMJ Open. 2015;5:e08615.

15. Shilling V, Bailey S, Logan S, et al. Peer support for parents of disabled children part 2: how organizational and process factors influenced shared experience in a one-to-one service, a qualitative study. Child Care Health Dev. 2015;41:537-46.

16. Shilling V, Bailey S, Logan S, et al. Peer support for parents of disabled children part 1: perceived outcomes of a one-to-one service, a qualitative study. Child Care Health Dev. 2015;41:524-36.

17. Shilling V, Morris C, Thompson-Coon J, et al. Peer support for parents of children with chronic disabling conditions: a systematic review of quantitative and qualitative studies. Dev Med Child Neurol. 2013;55:602-9.

18. INVOLVE. Involving children and young people. Web page: http://www.invo.org.uk/find-out-more/how-to-involve-people/ involving-children-and-young-people/. [date access 16.02.2017]. 2017.
19. Staniszewska S, Brett J, Simera I, et al. GRIPP2 reporting checklists: tools to improve reporting of patient and public involvement in research. BMJ. 2017;358:j3453.

20. Rahimzadeh V, Bartlett G, Longo C, et al. Promoting an ethic of engagement in pediatric palliative care research. BMC Palliat Care. 2015; $14: 50$.

21. Stevens K. Developing a descriptive system for a new preferencebased measure of health-related quality of life for children. Qual Life Res. 2009;18:1105-13.

22. Stevens K. Assessing the performance of a new generic measure of health-related quality of life for children and refining it for use in health state valuation. Appl Health Econ Health Policy. 2011;9:157-69.

23. Stevens K. Valuation of the Child Health Utility 9D Index. Pharmacoeconomics. 2012;30:729-47.

24. Oddone E, Weinberger M, Hurder A, et al. Measuring activities in clinical-trials using random work sampling-implications for cost-effectiveness analysis and measurement of the intervention. J Clin Epidemiol. 1995;48:1011-8.

25. Boote J, Baird W, Sutton A. Involving the public in systematic reviews: a narrative review of organizational approaches and eight case examples. J Comp Eff Res. 2012;1:409-20.

26. Pearson M, Monks T, Gibson A, et al. Involving patients and the public in healthcare operational research-The challenges and opportunities. Operations Research for Health Care. 2013; 2.

27. van Voorn GA, Vemer P, Hamerlijnck D, et al. The Missing Stakeholder Group: why Patients Should be Involved in Health Economic Modelling. Appl Health Econ Health Policy. 2016;14:129-33.

28. Erdem S, Campbell D. Preferences for public involvement in health service decisions: a comparison between best-worst scaling and trio-wise stated preference elicitation techniques. Eur J Health Econ. 2016.

29. Faulkner A YS, Kalathil J, Crepaz-Keay D, Singer F, James N, Griffiths R, Perry E, Forde D, Kallevik J. Involvement for Influence., 4PI National Involvement Standards. London: National survivor user network (NSUN), 2015.

30. Mullins CD, Abdulhalim AM, Lavallee DC. Continuous patient engagement in comparative effectiveness research. JAMA. 2012;307:1587-8.

31. Institute of Medicine (US). Patients Charting the Course: Citizen Engagement and the Learning Health System: Workshop Summary. In: Olsen L, Saunders R, McGinnis J, eds. Washington (DC): National Academies Press (US). Available from: https:// www.ncbi.nlm.nih.gov/books/NBK92072/, 2011.

32. Haywood K, Brett J, Salek S, et al. Patient and public engagement in health-related quality of life and patient-reported outcomes research: what is important and why should we care? Findings from the first ISOQOL patient engagement symposium. Qual Life Res. 2015;24:1069-76.

33. Pizzo E, Doyle C, Matthews R, et al. Patient and public involvement: how much do we spend and what are the benefits? Health Expect. 2015;18:1918-26.

34. Carman KL, Dardess P, Maurer M, et al. Patient and family engagement: a framework for understanding the elements and developing interventions and policies. Health Aff (Millwood). 2013;32:223-31. 